\title{
Vibrational spectra of some binary semiconducting oxide glasses
}

\author{
A. MEMON, M. N. KHAN, K. E. RAJAB* \\ Department of Physics, and ${ }^{*}$ Department of Mechanical and Chemical Engineering, \\ University of Bahrain, Bahrain \\ D. B. TANNER \\ Department of Physics, University of Florida, Gainesville, U.S.A
}

\begin{abstract}
The frequency-dependent complex relative permittivities of binary semiconducting $\mathrm{V}_{2} \mathrm{O}_{5}-\mathrm{P}_{2} \mathrm{O}_{5}$ glasses containing various amounts of vanadium have been measured at ambient temperature in the infrared region by power reflection spectroscopy. The measured values of the static constant, $\varepsilon_{0}$, and high frequency constant, $\varepsilon_{x}$, are used to calculate the small polaron binding energy, $W_{p}$, and the activation energy for conduction in the vanadium phosphate glasses, and comparisons are made with published data.
\end{abstract}

\section{Introduction}

Oxide glasses containing transition metal ions were first reported in 1954 [1]. Many transition-metal oxides form glasses when melted with proportions of $\mathrm{P}_{2} \mathrm{O}_{5}$ in which the transition metal ions are major constituents. Vanadium pentoxide is oxygen deficient when nonstoichiometric, the extra electrons being localized at $\mathrm{V}^{5+}$ centres resulting in the formation of reduced vanadium ions, normally $\mathrm{V}^{4+}$, unless extremely reduced conditions are used [2]. Electrical conduction in these glasses occurs by electron hopping from an ion valence state $\left(\mathrm{V}^{4+}\right)$ transition metal to an ion of the high valence state $\left(\mathrm{V}^{5+}\right)$ [3].

Several groups [4-7] have investigated glass systems and a reasonably clear picture of the conduction mechanism in the glasses has emerged. It has been suggested [8] that the glass-forming oxide might not be a non-interacting solvent in the conduction process, as described by Ioffee et al. [9] for the $\mathrm{V}_{2} \mathrm{O}_{5}-\mathrm{P}_{2} \mathrm{O}_{5}$ system. In a previous paper [10] we have reported spectroscopic studies of vanadate glasses and found that by adding $\mathrm{VCl}_{3}$ to the melt when the glass is formed, the added chlorine, which acts as an oxidizing agent, alters the ratio of concentration of vanadium ions and thus the optical absorption edge and the conductivity. In the present paper we report the results of our measurements on binary $\mathrm{V}_{2} \mathrm{O}_{5}-\mathrm{P}_{2} \mathrm{O}_{5}$ glasses containing various amounts of vanadium. The frequencydependent complex relative permittivities have been measured in the infrared region by power reflection spectroscopy.

The measured values of static and high-frequency dielectric constant are used to calculate the small polaron binding energy and the activation energy for conduction in vanadium phosphate glasses.

\section{Experimental procedure}

The series of binary $\mathrm{V}_{2} \mathrm{O}_{5}-\mathrm{P}_{2} \mathrm{O}_{5}$ glass samples containing 50 to $70 \mathrm{~mol} \% \mathrm{~V}_{2} \mathrm{O}_{5}$ was prepared from a chemi- cally pure grade of materials. The crucible containing the mixture was pre-heated at $300^{\circ} \mathrm{C}$ for $1 \mathrm{~h}$ and then placed in a closed high-temperature furnace where it was held for $6 \mathrm{~h}$ at a temperature of about $950^{\circ} \mathrm{C}$. The melt was stirred from time to time using an alumina rod. By slow heating it was hoped to reduce mechanical and volatilization losses. The melts were finally poured on to a clean stainless steel plate and cast into the shape of discs $20 \mathrm{~mm}$ diameter and 2 to $3 \mathrm{~mm}$ thick. Two discs of each composition were cast, one on a stainless steel plate which was at room temperature and the other on a steel plate maintained at a temperature of $200^{\circ} \mathrm{C}$ and introduced into a furnace which was already at this temperature. The furnace was maintained at this temperature for $2 \mathrm{~h}$ and was then switched off to cool down to room temperature. The samples were polished optically flat for the infrared measurements. The reflectance for these samples was measured with a Michelson interferometer in the far infrared region and a grating monochrometer in the infrared region. The frequency-dependent dielectric response function was determined by KramersKronig analysis [11].

\section{Results and discussion}

The power reflection coefficient, $R$, for the vanadate glasses was measured at near normal incidence in the range 100 to $5000 \mathrm{~cm}^{-1}$. The high signal-to-noise ratio of our instrument, due to the liquid helium detector, allows us to measure precisely the small reflectivity in this spectral range.

The measured frequency-dependent dielectric response function of $\mathrm{V}_{2} \mathrm{O}_{5}-\mathrm{P}_{2} \mathrm{O}_{5}$ glasses for $50 \mathrm{~mol} \%$ concentration, both annealed and unannealed, are shown in Figs 1 and 2, respectively. The following procedure was adopted to obtain the dielectric functions from the measured reflectance.

The phase, $\theta$, of the measured amplitude reflection coefficient, $R$, at frequency $\omega$ is related to $R$ using the 


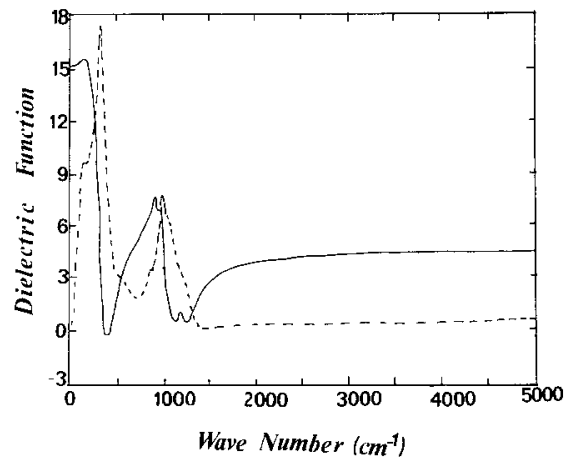

Figure 1 The infrared complex dielectric response function of annealed $\mathrm{V}_{2} \mathrm{O}_{5}-\mathrm{P}_{2} \mathrm{O}_{5}$ glass. $\left(-\varepsilon_{1},(--) \varepsilon_{2}\right.$.

Kramers-Kronig analysis

$$
\theta(\omega) \frac{\omega}{\pi} \int_{0}^{x} \frac{\ln R\left(\omega^{\prime}\right) \mathrm{d} \omega^{\prime}}{\omega^{2}-\omega^{2}}
$$

The real and imaginary parts of dielectric functions, $\varepsilon_{1}(\omega)$ and $\varepsilon_{2}(\omega)$, are related to $R$ and $\theta$ through the complex refractive index $(N+i K)$ as

$$
N(\omega)=\frac{1-R}{1-2 R^{1 / 2} \cos \theta+R}
$$

and

$$
K(\omega)=\frac{2 R(\sin \theta)^{1 / 2}+R}{1-2 R^{1 / 2} \cos \theta+R}
$$

also

$$
\varepsilon_{1}(\omega)+i \varepsilon_{2}(\omega)=\left[N(\omega)^{2}+i K(\omega)^{2}\right]^{2}
$$

In theory one needs $R$ from 0 to $\infty$, and not for the region for which the measurements are performed. One can justify some extrapolation because the power reflection coefficient reduces rapidly from the frequency in question.

We have used Equations 1 to 3 to calculate the frequency-dependent dielectic response function. At high frequency, i.e. above $4000 \mathrm{~cm}^{-1}$, there is no strong absorption mechanism, and hence $\varepsilon_{1}(\omega)$ attains a constant value, which leads us to estimate the frequency dielectric constant, $\varepsilon_{\infty}$ : for our calculation of polaron binding energy, the effective dielectric constant, $\varepsilon_{p}$, can be approximated only from $\varepsilon_{x}$, i.e. $\varepsilon_{\mathrm{p}}=\varepsilon_{x_{\mathrm{s}}}=N^{2}$, because in the relation

$$
\frac{1}{\varepsilon_{\mathrm{p}}}=\frac{1}{\varepsilon_{x_{0}}}-\frac{1}{\varepsilon_{0}}
$$

$\varepsilon_{0}$ is very high as compared to $\varepsilon_{x}$. We also used the normal extrapolation procedure to calculate $\varepsilon_{0}$. The calculated values of $\varepsilon_{0}$ and $\varepsilon_{\infty}$ are 15.5 and 4.5 , respectively, for $\mathrm{V}_{2} \mathrm{O}_{5}-\mathrm{P}_{2} \mathrm{O}_{5}$ vanadate glass of $50 \mathrm{~mol} \% \mathrm{con}$ centration, and this can be seen in Fig. 1. In transition metal oxide glasses, strong interaction between the

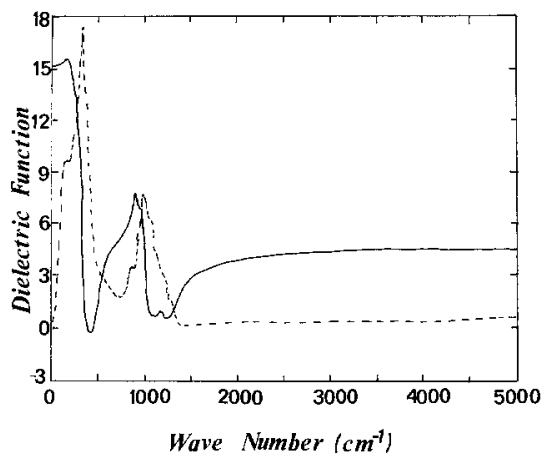

Figure 2 The infrared complex dielectric response function of unannealed $\mathrm{V}_{2} \mathrm{O}_{5}-\mathrm{P}_{2} \mathrm{O}_{5}$ glass. (-) $\varepsilon_{1},(---) \varepsilon_{2}$.

unpaired electrons and the lattice leads to the polarization of the lattice and displacement of the oxygen ions around the low valence transition metal ion. This localization process is sufficient to produce a small polaron. The theory of small polaron in transition metal oxides is discussed in detail by Mott [12] and Austin and Mott [13].

The measured value of $\varepsilon_{\infty}$, together with the calculated value of $r_{\mathrm{p}}$, the polaron radius, enable us to calculate the polaron binding energy, $W_{\mathrm{p}}$. Several authors [12-14] calculated the small polaron radius, $r_{\mathrm{p}}$, using the relation

$$
r_{\mathrm{p}}=1 / 2(\pi / 6 N)^{1 / 3}
$$

where $N$ is the concentration of vanadium ions in the glass. This concentration can be calculated using the relation $[15]$

$$
N=\frac{\varrho V_{2} N_{0}}{\text { at. wt } \times 100}
$$

where $\varrho$ is the density of the glass in question, $V_{2}$ is the weight per cent of vanadium in the glass, $N_{0}$ is the Avogadro number, and at. wt is the atomic weight of $V_{2}$. Equations 4 and 5 , together with the measured value of $\varepsilon_{x}$, are used to calculate the polaron hopping energy, $W_{\mathrm{H}}[16]$

$$
W_{\mathrm{H}}=1 / 4 \frac{e^{2}}{\varepsilon_{\mathrm{p}}}\left(\frac{1}{r_{\mathrm{p}}}-\frac{1}{R}\right)
$$

where $R$ is the mean distance between transition metal ions which was determined from a composition found by chemical analysis and density measurement. (This assumes that transition metal ions are uniformly distributed.) The polaron hopping energy is related to the polaron binding, $W_{\mathrm{p}}$, as $2 W_{\mathrm{H}}=W_{\mathrm{p}}$. The activation, $W$, can also be written in terms of $W_{\mathrm{H}}$ and $W_{\mathrm{D}}$, the disordered energy, as [16]

$$
W=W_{\mathrm{H}}+1 / 2 W_{\mathrm{D}}
$$

For $\mathrm{V}_{2} \mathrm{O}_{5}-\mathrm{P}_{2} \mathrm{O}_{5}$ disorder, $W_{\mathrm{D}}=0.1 \mathrm{eV}$ [12]. The

TABLE I Physical parameters of binary vanadate glasses

\begin{tabular}{lllllllll}
\hline $\begin{array}{l}\mathrm{V}_{2} \mathrm{O}_{5} \\
(\mathrm{~mol} \%)\end{array}$ & $\begin{array}{l}\mathrm{P}_{2} \mathrm{O}_{5} \\
(\mathrm{~mol} \%)\end{array}$ & $\begin{array}{l}\text { Density of } \\
\text { glass }\left(\mathrm{g} \mathrm{cm}^{-3}\right)\end{array}$ & $N\left(10^{22} \mathrm{~cm}^{-3}\right)$ & $r_{\mathrm{p}}(\mathrm{nm})$ & $R(\mathrm{~nm})$ & $W_{\mathrm{H}}(\mathrm{eV})$ & $W_{\mathrm{p}}(\mathrm{eV})$ & $W(\mathrm{eV})$ \\
\hline 50 & 50 & 2.80 & 1.04 & 0.184 & 0.456 & 0.260 & 0.52 & 0.310 \\
60 & 40 & 2.83 & 1.23 & 0.174 & 0.432 & 0.273 & 0.546 & 0.323 \\
70 & 30 & 2.87 & 1.42 & 0.166 & 0.411 & 0.286 & 0.572 & 0.336 \\
\hline
\end{tabular}


values of $r_{\mathrm{p}}, R, W_{\mathrm{H}}, W_{\mathrm{p}}$ and $W$ calculated from Equations 4 to 6 , are listed in Table I. The observed values are in clear agreement with the published data $[16,17]$. The infrared absorption spectrum of the vanadate glasses is well established $[10,18]$. The observed peaks in the imaginary part of the dielectric function in Figs 1 and 2 correspond to the infrared absorption peak for such glasses. Assignment of such absorption bands can be found in [18].

\section{Conclusions}

Power reflection spectroscopy provides an alternative method for determining the high-frequency dielectric constant, and hence the effective dielectric constant, $\varepsilon_{\mathrm{p}}$, which can be used in addition to Equation 7 to estimate the polaron binding energy and the activation energy for conduction in glasses.

The polaron parameters calculated for $\mathrm{V}_{2} \mathrm{O}_{5}-\mathrm{P}_{2} \mathrm{O}_{5}$ glasses appear reasonable, and are in agreement with the values reported in the literature.

\section{References}

1. E. P. DENTON, H. ROWSON and J. E. STANWORTH Nature 173 (1954) 1030.

2. H. HARPER and P. W. MCMIBLAN, ibid. 15(6) (1974) 148.

3. I. G. AUSTIN and N. F. MOTT, Adv. Phys. 18 (1969) 41 .
4. G. S. LINSLEY, A. E. OWEN and F. M. HAYATEE, J. Non-Cryst. Solids 4 (1970) 208.

5. M. SAYER and A. MANSINGH, Phys. Rev. B6 (1971) 4629.

6. G. N. GREAVES, J. Non-Cryst. Solids 11 (1973) 427.

7. J. D. MACKENZIE, "Modern Aspects of the Vitreous State" (Butterworth, London, 1965) p. 126.

8. B. W. FLYNN, A. E. OWEN and J. M. ROBERTSON, in "Proceedings of the International Conference on Amorphous and Liquid Semiconductors", edited by W. E. Spear (CICL, Edinburgh, 1977) p. 678.

9. V. A. IOFFE, J. B. PATRINA and I. S. ROBEROV. SHAYA, Sov. Phys. Solid State 2 (1960) 609.

10. N. N. KHAN and A. MEMON, J. Mater. Sci. 22 (1987) 3309.

11. T. S. ROBINSON and W. C. PRICE, Proc. Phys. Soc, B66 (1953) 969.

12. N. F. MOTT, J. Non-Cryst. Solids 1 (1968) 1.

13. G. N. GREAVES, ibid. 11 (1973) 427.

14. V. N. BOGMOLOV, E. K. KUDINOV and Y. A. FKISOV, Sov. Phys. Solid State 9 (1968) 2502.

15. H. NESTER and W. D. KINGERLY, in "Proceedings of the International Congress on Glass VII", Brussels (Grordon and Breach, New York, 1965) p. 106.

16. C. H. CHUNG and J. D. MACKENZI, J. Non-Cryst. Solids 42 (1980) 357.

17. L. MURAWSKI, ibid. 90 (1987) 629.

18. K. NAKAMOTO, "Infrared Spectra of Inorganic and Coordination Compounds" (Wiley, New York, 1963).

Received 1 November 1988

and accepted 14 April 1989 